\title{
Modelo de insolvência aplicado a organizações cooperativas médicas: análise do mercado brasileiro
}

\author{
Insolvency model applied to medical cooperative organizations: brazilian market analysis
}

\begin{abstract}
Resumo
As cooperativas médicas Operadoras de Planos de Saúde brasileiras, estão sujeitas, como toda e qualquer Operadora de Plano de Saúde, aos riscos inerentes ao mercado de Planos de Saúde Suplementar, além de uma rígida regulação deste segmento tão importante aos brasileiros. Nesse contexto, o presente artigo, tem como objetivo identificar dentre os modelos de insolvência comumente aplicados às empresas, qual teria o melhor desempenho em prever a Insolvência de Cooperativas Médicas Operadoras de Planos de Saúde. Como base de dados, foram utilizadas as demonstrações financeiras das Cooperativas Médicas Brasileiras que enviaram dados à Agência Nacional de Saúde (ANS) no período de 2010 a 2017 , totalizando a média de 310 instituições por ano. Foram aplicados 6 modelos clássicos de previsão de Insolvência. Como resultado, os modelos com melhor desempenho, foram: O proposto por Matias, Altman, Baidya e Dias e em seguida Guimarães e Alves. Os modelos apresentaram forte equiparação de análises focados no trabalho com destaque para o modelo que tinha tecnicamente regressão logística direcionado a análise de Operadoras de Planos de Saúde (OPS). Porém apresentando baixa sensibilidade em classificação de insolventes, necessitando analisar este outro ponto com outro modelo mais aderente ao processo.
\end{abstract}

Palavras-chave: cooperativismo, insolvência, cooperativas médicas, operadoras de planos de saúde.

\begin{abstract}
Brazilian health plan operators, like all Health Care Operators, are subject to the risks inherent in the Supplementary Health Plans market, in addition to a rigid regulation of this segment so important to Brazilians. In this context, this article aims to identify among the models of insolvency commonly applied to companies, which would have the best performance in predicting the Insolvency of Medical Cooperatives Operators of Health Plans. Brazilian Medical Cooperatives that sent data to National Agency Health Care (ANS) in the period from 2010 to 2017, totaling an average of 310 institutions per year. Six models of insolvency prediction were applied. As a result, the models with the best performance were: Matias, followed by the one proposed by Altman, Baidya and Dias and then the model Guimarães and Alves. The models presented a strong analysis of the work focused on the model that had a logistic regression technique directed to the analysis of Operators of (OPS) Health Plans. However, it presents low sensitivity in insolvency classification, needing to analyze this other point with another model more adherent to the process.
\end{abstract}

Keywords: cooperativism. insolvency, medical cooperatives, operators of health plans.

Alexandre Moreira Batista ${ }^{\text {I }}$, June Alisson Westarb Cruz ${ }^{\text {II }}$, Pedro Guilherme Ribeiro Piccoli ${ }^{\mathrm{III}}$.

I Pontifícia Universidade Católica do Paraná- PUCPR. Paraná, PR. alexandre.batista@unimedcuritiba.com.br

II Pontifícia Universidade Católica do Paraná- PUCPR. Paraná, PR. june.cruz@pucpr.br

III Pontifícia Universidade Católica do Paraná- PUCPR. Paraná, PR. pedro.guilherme@pucpr.br 


\section{Introdução}

O sistema de saúde brasileiro é estruturado em duas grandes categorias de prestadores de serviços. A primeira é denominada Sistema Único de Saúde (SUS), a qual promove o direito a todo e qualquer cidadão do acesso a serviços de saúde, sejam eles de atenção primária, secundária ou terciária. No SUS, os serviços são prestados de forma gratuita à população, por meio da aplicação direta de recursos públicos. A segunda categoria, objeto da presente pesquisa, é denominada Saúde Suplementar, sendo ofertada por grupos privados e entidades cooperativas, que prestam serviços de saúde mediante os denominados Planos de Saúde, cuja origem do recurso é do próprio beneficiário do Plano (CHAVES et al., 2017).

A Saúde Suplementar no Brasil, tem grande importância no sistema de Saúde. Dados da Agência (ANS, 2017), mostram que o país teve 47,7 milhões de beneficiários de Planos de Saúde distribuídos em 959 Operadoras de Planos de Saúde (OPS) em junho de 2017, significando que cerca de $25 \%$ da população brasileira é usuária da Saúde Suplementar. Embora os quantitativos pareçam generosos, em decorrência da constante crise econômica do país, percebe-se uma crescente evasão de usuários da Saúde Suplementar, insolvência nas operadoras e aumentando a quantidade de usuários do Sistema Único de Saúde, excesso de demanda e consequente diminuição da qualidade assistencial dos serviços prestados (ANS, 2017).

Tal fenômeno ressalta a importância em avaliar com antecedência quais Operadoras de Saúde Suplementar têm probabilidades de Insolvência. Neste sentido, inspirado pela pesquisa de Barros e Beiruth (2016), o presente trabalho tem como objetivo central, identificar o modelo de Previsão de Insolvência que melhor se aplica às Cooperativas Médicas Brasileiras. Para tanto, utilizou-se os Demonstrativos Financeiros das empresas, por meio do sistema DIOPS - Documento de Informações Periódicas das Operadoras de Planos de Assistência à Saúde, oriundos do Site da Agência (ANS, 2017).

A aspiração de identificar o melhor modelo de previsibilidade de insolvência, é motivada pela crença de contribuir, por meio de métodos financeiros e econométricos, para a melhoria do sistema de saúde como um todo, auxiliando na qualificação da assistência em saúde, por meio de suas instituições (CRUZ; ANDRICH; MUGNAINI, 2019).

\section{Abordagem teórica}

A presenta seção demonstra o contexto geral e específico das principais referências teóricas vinculadas à pesquisa, separadas nos seguintes tópicos: Cooperativas de Saúde Brasileiras; Insolvência e Mercado de Operadoras de Saúde; e Modelos de Insolvência Aplicados a Operadoras de Saúde: Análise Integrada.

\subsection{Cooperativas de saúde brasileiras}

No sentido de melhor classificar as cooperativas a OCB, entidade que representa todas as cooperativas do Brasil, define a divisão em 13 ramos. Um deles é o ramo saúde, que foram as cooperativas objeto de estudo dessa pesquisa.

O mercado de planos de saúde pode ser agrupado como as seguradoras de saúde, as empresas de medicina de grupo, as cooperativas médicas e as entidades de autogestão. Estas organizações vendem planos de saúde que intermedeiam o movimento de acesso aos serviços privados de saúde. Elas protegem os segurados do custo vinculado ao risco de adoecer. Pelo princípio do mutualismo, as famílias e pessoas jurídicas responsáveis pelo pagamento das contraprestações dos planos de saúde, ficam protegidas contra desembolsos de valores extremos destes custos. 
Dentre estes grupos, as cooperativas de saúde dedicam-se à preservação e promoção da saúde e ao direcionamento de trabalho ao seu corpo de médicos cooperados. Segundo (VIANA et al., 2012) no Brasil os sistemas de cooperativas de saúde são os mais desenvolvidos do mundo. Além das Unimed's e Uniodonto, existem numerosas cooperativas locais que agregam médicos da mesma especialidade (anestesiologistas por exemplo) ou que trabalham num mesmo hospital ou órgão público.

A primeira cooperativa de trabalho médico do país e também das Américas foi a União dos Médicos, Unimed fundada na cidade de Santos (SP) em 1967 (UNIMED, 2017), que marca o surgimento de um modelo de organização empresarial cooperativo, diferente das demais OPS. Já na década de 70 surgiram as federações Unimed visando padronizar procedimentos operacionais e estimular a troca de experiência entre cooperativas do mesmo estado. Em 28 de novembro de 1975 foi criada a Confederação Nacional das Cooperativas médicas - Unimed do Brasil, entidade máxima do sistema Unimed que congrega federações e singulares de todo país.

Segundo Bialoskorski (2012), para analisar as cooperativas, é necessário avaliar os fatores que levaram à formação e manutenção da empresa nesta forma de arquitetura. Pelo viés da Teoria dos Jogos, a cooperação voluntária é o ponto de equilíbrio descrito como "dilema do prisioneiro". Nesta visão a cooperação traz resultados melhores a ambos. Da mesma forma o autor acima coloca a cooperação como uma forma de "alocar custos e benefícios pelos seus diversos associados, enquanto se preservam os incentivos para a proteção da organização". Nas cooperativas, os sócios são os que detêm os direitos aos fluxos de rendimentos gerados, assim como, têm o dever sobre os prejuízos gerados.

Atualmente o Brasil tem um sistema de cooperativas de grande porte. Os números apontam 6.586 cooperativas, com mais de 10 milhões de associados e empregam diretamente mais de 30.000 pessoas. O sistema é organizado hierarquicamente em três níveis de cooperativas: Singular ou de $\mathbf{1}^{\mathbf{0}}$ (grau associações formadas por pelo menos 20 pessoas físicas são a base do sistema), Federação ou de $2^{\circ}$ grau (formadas por pelo menos três cooperativas singulares), prestam serviços a suas afiliadas, especialmente programas de capacitação e que envolvam investimento em comum, Confederação ou de $3^{\circ}$ grau (formadas por pelo menos 3 federações) organizam e prestam serviços de grande escala às suas afiliadas.

As cooperativas médicas no Brasil, são sociedades de pessoas sem fins lucrativos constituídas conforme o disposto na Lei $n^{\circ} 5.764 / 71$ (Lei geral do cooperativismo), que operam planos privados de assistência à saúde. Por meio desta estrutura jurídica, a classe médica, pode operar os convênios com as empresas e pessoas físicas, transformando esses profissionais em sócios dos resultados financeiros da cooperativa e em prestadores de serviços à empresa de que são sócios, simultaneamente.

A totalidade de ativos que envolvem essas instituições no Brasil, corresponde a valor aproximado de US $\$ 4,5$ bilhões em 2010 para US\$ 8,2 bilhões em 2016. O modelo de estrutura de capital em cooperativas é diferente das demais OPS. Neste sentido é interessante notar que em termos de ativos totais, as cooperativas médicas representam $26,4 \%$ do total das OPS (em 2016), enquanto em termos de Receitas Totais, este percentual sobe para 37,4\%, atingindo R\$ 64 bilhões, frente a R\$120 bilhões das demais modalidades de OPS no mesmo ano.

\subsection{Insolvência e mercado de operadoras de saúde}

Segundo Barros e Beiruth (2016), vários autores abordam sobre as causas pelas quais as empresas entram em falência. Andrich et al., (2014) relata acerca da complexidade da liquidez da empresa, da liquidez do ativo e da causa da insolvência, já que o inadimplemento é o primeiro sintoma da baixa de liquidez numa empresa (CRUZ; ANDRICH; SCHIER, 2019). A insolvência de uma empresa como o momento em que ela se torna incapaz de honrar com seus compromissos sem afetar o capital investido pelos seus acionistas (LEV, 1968). 
Mais especificamente, no mercado de planos de saúde, verifica-se um alto risco de negócio, e isso ocorre devido a diversos fatores como procedimentos de alta complexidade, entrada de novas tecnologias, inflação médica elevada, envelhecimento da população, novas regulações financeiras perante ANS, ente outros. Com isso, algumas operadoras de planos de saúde passaram por problemas financeiros, se mostraram insolventes e com dificuldades para arcar com os compromissos.

O surgimento de modelos de previsão de insolvência é antigo, datados da década de 3o, advindos da necessidade de resguardar os interesses dos atores que se relacionavam no mercado (ANDRICH; CRUZ, 2013).

Entretanto, tais modelos só ganharam relevância a partir da década de 60 com a utilização de técnicas estatísticas (PINHEIRO et al., 2007). (BEAVER, 1966) e (ALTMAN, 1968) foram os pioneiros a utilizarem os modelos estatísticos de previsão de insolvência, sendo que Beaver (1966) utilizou técnicas uni variadas e Altman (1968) técnicas multivariadas. Com base nos trabalhos de Elizabetsky (1976), Kanitz (1978) e Matias (1976) pode-se dizer que são pioneiros em sua época no Brasil.

Segundo Barros e Beiruth (2016), para as OPS não existiam nenhum outro modelo de previsão de insolvência descrito utilizando dados financeiros até a publicação do trabalho de Guimarães e Alves (2009), que apresentaram um novo modelo de previsão de insolvência avaliando 17 indicadores financeiros. Os resultados do modelo desenvolvido foram comparados ao modelo do escore "Z" de Altman e obtiveram uma acurácia superior (GUIMARÃES; ALVES, 2009).

Apesar de existirem advertências sobre a utilização de dados contábeis (AHERN, 1991) apud (GUIMARÃES; ALVES, 2009) nos modelos de previsão de insolvência, Kanitz (1978) conclui que as demonstrações contábeis sendo totalmente fidedignas, são de extrema importância, pois a capacidade de previsão é alta quando comparamos empresas do mesmo setor (BARROS; BEIRUTH, 2016).

Ainda no trabalho de (BARROS; BEIRUTH, 2016), foi possível verificar que existem evidências de que o Patrimônio Líquido é aceitável como indicador de previsão de insolvência para utilizar como variável no estudo, já que conseguiu diferenciar com segurança o grupo das OPS solventes do grupo das insolventes.

A presente pesquisa considerou a aplicação dos modelos estudados por (BARROS; BEIRUTH, 2016) de previsão de Insolvência propostos por (ELIZABETSKY, 1976), (MATIAS, 1976), (KANITZ, 1978), (ALTMAN; BAIDYA; DIAS, 1979), (SANVICENTE; MINARDI, 1998) e (GUIMARÃES; ALVES, 2009). Para tanto, a aplicação do modelo de (BARROS; BEIRUTH, 2016), a amostra foi de 782, 752, 721, 763 OPS para os anos de 2009, 2010, 2011 e 2012 respectivamente. A seguir são apresentadas, de forma objetiva, as principais características técnicas de cada um dos modelos utilizados.

\subsubsection{Modelagem Proposta por: Guimarães e Alves (2009)}

A modelagem proposta por (GUIMARÃES; ALVES, 2009) foi a primeira metodologia no Brasil a ser desenvolvida exclusivamente para OPS. Os autores desenvolveram um modelo de previsão de insolvência focado especificamente em OPS. A técnica estatística utilizada foi de regressão logística, por meio do uso de 17 indicadores financeiros faziam parte do modelo. A amostra foi de aproximadamente 706 operadoras brasileiras de planos de saúde. A base de dados da ANS apontava mais de 1.000 OPS, mas em torno de 300 eram exclusivamente de odontologia e desta forma foram excluídas da amostra.

O objetivo foi desenvolver um modelo para prever a insolvência de uma operadora no ano seguinte ao analisado. O processo foi de considerar os dados de 2004 e prever a insolvência do ano 2005. Como a base da modelagem foi à regressão Logística, as OPS foram classificadas como 
( solvente $=\mathrm{o}$, insolvente $=1$ ). Neste estudo, os autores consideram a OPS insolvente ou solvente segundo o seu PL. Quando o valor de seu patrimônio líquido, após um ano, é inferior ou igual zero, ela foi considerada insolvente, enquanto quando o seu patrimônio líquido foi maior que zero, ela foi considerada solvente. O modelo de Regressão Logística final foi composto de 3 variáveis, e pode ser descrito na forma abaixo (1):

$$
\begin{gathered}
\log (\mathrm{PI} / 1-\mathrm{PI})=-4,834+1,206 \times \log (\mathrm{PC} / \mathrm{PL})-5,716 \times(\mathrm{LL} / \mathrm{AT})+0,242 \times(\mathrm{RT} / \mathrm{AT})(1) \\
\mathrm{AT}=\text { Ativo Total } \\
\mathrm{LL}=\text { Lucro Líquido; } \\
\mathrm{PI}=\text { Probabilidade de Insolvência; } \\
\text { PC = Passivo Circulante (excluindo-se as provisões }) ; \\
\mathrm{PL}=\text { Patrimônio Líquido; } \\
\mathrm{RT}=\text { Receita Total (Líquida) }
\end{gathered}
$$

Os valores sugeridos para separação, segundo os autores são (GUIMARÃES; ALVES, 2009, p. 467):
a. Vermelho (alta probabilidade de insolvência): maior que o,040
b. Amarelo (alguma probabilidade de insolvência): entre 0,025 e 0,040
c. Verde (insolvência improvável): menor que o,025

De modo a comparar e entender o poder de previsão, foi selecionada uma segunda amostra com 745 OPS, sendo 20 delas insolventes. O modelo específico então foi comparado a um modelo bastante popular, o escore "Z" de Altman.

Com esta nova base de testes, o modelo proposto por (GUIMARÃES; ALVES, 2009) teve um desempenho superior ao Escore Z de Altman. Em termos de Razão de Acurácia, o modelo específico para OPS obteve $69,65 \%$ e o Escore de Altman $68,77 \%$. Os autores concluíram que o modelo específico para OPS tem desempenho superior ao Escore Z de Altman, que é uma modelagem clássica utilizada há mais de 50 anos.

\subsubsection{Modelagem Proposta por: Elizabetsky (1976)}

Neste modelo, o autor fez uso da Análise Discriminante como técnica estatística. O objetivo foi a utilização no setor de crédito de um banco. Em seu trabalho, (ELIZABETSKY, 1976) considerou uma amostra de 373 empresas, sendo estas do setor de confecções, pois o setor apresentava graves problemas de liquidez. Destas empresas, foram 274 empresas classificadas como tendo boas condições financeiras, e 99 empresas como tendo más condições financeiras.

No modelo inicial o autor utilizou 38 indicadores financeiros, sendo que o modelo final ficou com 5 variáveis eleitas como relevantes para previsão de insolvência (2). Neste estudo o autor considerou como ponto de corte de seu modelo discriminante o escore de 0,5 .

$$
\begin{gathered}
\mathrm{Z}=1,93 \mathrm{X}_{1}-0,21 \mathrm{X}_{2}+1,02 \mathrm{X}_{3}+1,33 \mathrm{X}_{4}-1,13 \mathrm{X}_{5}(2) \\
\mathrm{X}_{1}=\text { lucro líquido/vendas } \\
\mathrm{X}_{2}=\text { disponível/ativo permanente } \\
\mathrm{X}_{3}=\text { contas a receber/ativo total } \\
\mathrm{X}_{4}=\text { estoque/ativo total } \\
\mathrm{X}_{5}=\text { passivo circulante/ativo total }
\end{gathered}
$$

\subsubsection{Modelagem Proposta por: Matias (1976)}

No modelo de Matias (1976), o autor utilizou também a análise discriminante. A amostra foi de 100 empresas de ramos de atividades diferentes, das quais 50 eram solventes e 50 insolventes, 
entre o período de 1977 e 1978. Seu objetivo foi de uma contribuição teórica de modo a aperfeiçoar a concessão de crédito às pessoas jurídicas. A precisão do modelo foi de $75 \%$. A equação do modelo está descrita da seguinte forma (3):

$$
\begin{gathered}
\mathrm{Z}=23,792 \mathrm{X}_{1}-8,26 \mathrm{X}_{2}-9,868 \mathrm{X}_{3}-0,764 \mathrm{X}_{4}-0,535 \mathrm{X}_{5}+9,912 \mathrm{X} 6 \text { (3) } \\
\mathrm{X} 1 \text { = Patrimônio líquido/Ativo total } \\
\mathrm{X}_{2}=\text { Financiamento e empréstimos bancários / Ativo circulante } \\
\mathrm{X}_{3}=\text { Fornecedores } / \text { Ativo Total } \\
\mathrm{X}_{4}=\text { Ativo Circulante /Passivo circulante } \\
\mathrm{X}_{5}=\text { Lucro operacional/lucro bruto } \\
\text { X6 = Disponível / Ativo total }
\end{gathered}
$$

Para o autor, o ponto discriminante é zero. No estudo a empresa que obteve valor acima de zero, foi considerada solvente. Caso o resultado da equação tenha um valor abaixo de zero, foi considerada insolvente.

\subsubsection{Modelagem Proposta por: Kanitz (1978)}

O modelo de Kanitz (1978) utilizou um modelo estatístico em uma equação matemática. Diferente dos modelos citados acima, o autor associou o uso de técnicas de regressão múltipla e análise discriminante. $\mathrm{O}$ objetivo deste modelo foi avaliar o risco de insolvência com um fator, que o autor descreveu como "Fator de Insolvência", indicando o que poderia acontecer em futuro próximo. Nos moldes do Escore Z de Altman, foi criado um termômetro de insolvência, considerando três possíveis situações: Solvência, Penumbra ou situação indefinida e Insolvência.

Sobre a amostra, o estudo utilizou 5.00o demonstrações financeiras de empresas brasileiras. Foram separadas 21 empresas aleatoriamente que haviam falido entre 1972 e 1974. Com um modelo final de análise discriminante, foram cinco as variáveis mais relevantes na explicação. O modelo de Kanitz pode ser demonstrado na seguinte equação (4):

$$
\begin{gathered}
\mathrm{FI}=0,05 \mathrm{X}_{1}+1,65 \mathrm{X}_{2}+3,55 \mathrm{X}_{3}-1,06 \mathrm{X}_{4}-0,33 \mathrm{X}_{5}(4) \\
\mathrm{X}_{1}=\text { Lucro Líquido } / \text { Patrimônio Líquido } \\
\mathrm{X}_{2}=(\text { Ativo Circulante }+ \text { Realizável em Longo Prazo }) / \text { Exigível total } \\
\mathrm{X}_{3}=(\text { Ativo Circulante }- \text { Estoques }) / \text { Passivo Circulante } \\
\mathrm{X}_{4}=\text { Ativo Circulante } / \text { Passivo Circulante } \\
\mathrm{X}_{5}=\text { Exigível total } / \text { Patrimônio Líquido }
\end{gathered}
$$

De acordo com o modelo, o autor definiu como o fator de insolvência calculado para uma empresa apresenta um valor entre (o) e (7), a empresa foi classificada como solvente. Se o fator apresentasse um valor entre (o) e (-3), a empresa seria classificada em uma região denominada penumbra ou indefinida. Da mesma forma, se o fator estivesse entre $(-3)$ e $(-7)$, a empresa seria considerada insolvente.

\subsubsection{Modelagem Proposta por: Altman, Baidya e Dias (1979)}

Os autores definiram como o propósito deste trabalho em examinar a experiência recente (à época) das falências no Brasil e desenvolver, testar e analisar um modelo quantitativo para classificar e prever problemas financeiros nas empresas (ALTMAN, BAIDYA; DIAS, 1979).

O estudo foi conduzido com análise discriminante, onde foram encontradas 23 empresas com problemas financeiros reconhecidos, e posteriormente outras 23 de mesmo ramo e portes para formar a amostra comparável de empresas sem problemas. Foram utilizados dados de balanço 
contábil do ano exatamente anterior ao ano que demonstrou problemas financeiros, e por consequência, dados deste mesmo ano da empresa sem problemas. Os anos foram de 1975 a 1977 .

O ponto crítico de separação dos grupos definido pelos autores é zero. Isto é, empresas com resultado da equação maior que zero foram classificadas no grupo de empresas Solventes e por consequência, as empresas com índice $\mathrm{Z}$ menor que zero foram classificadas como Insolventes. A equação de análise discriminante está descrita abaixo (5):

$$
\begin{gathered}
\mathrm{Z}_{1}=-1,44+4,03 \mathrm{X}_{2}+2,25 \mathrm{X}_{3}+0,14 \mathrm{X}_{4}+0,42 \mathrm{X}_{5} \text { (5) } \\
\mathrm{X}_{1}=\text { índice Capital de Giro Líquido / Ativo Total } \\
\mathrm{X}_{2}=\text { Reservas e Lucros Suspensos / Ativo Total } \\
\mathrm{X}_{3}=\text { Lucro antes de Juros e Impostos /Ativo Total } \\
\mathrm{X}_{4}=\text { Patrimônio Líquido / Ativo Total } \\
\mathrm{X}_{5}=\text { Vendas / Ativo Total }
\end{gathered}
$$

O procedimento de repetir a modelagem retirando apenas 1 das empresas e deixando as outras 57 foi feito repetidamente. E desta forma, foi usado o modelo sem aquela determinada empresa para prever a situação da mesma. Foi dado o nome de teste de validação para este procedimento. $\mathrm{O}$ resultado foi de $87 \%$ de precisão. O valor discriminante da equação é Zero. Porém os autores alertam para uma área de difícil precisão que está entre -0,34 e +o,20. Esta foi a faixa que gerou menor confiança na classificação.

\subsubsection{Modelagem Proposta por: Sanvicente e Minardi (1998)}

Os autores utilizaram informações contábeis de 92 empresas com ações negociadas na Bovespa-SP. Nesta base existiam 46 ações negociadas como concordatárias no período de 1986 a 1998, onde este foi o grupo de Insolventes. Para formar o grupo de empresas não concordatárias, ou Solventes, foi utilizado uma amostra emparelhada com o grupo anterior, sendo esta amostra estratificada por setor industrial. Os autores fizeram uso da classificação setorial do banco de dados da Economática (SANVICENTE; MINARDI, 1998).

Como na maioria dos modelos acima apresentados, os autores utilizaram a técnica estatística de Análise Discriminante nesta pesquisa. No início do estudo foram consideradas 14 variáveis independentes. No desenvolvimento da análise foi utilizado o Escore Z de Altman para comparação. Após a aplicação da técnica estatística, o modelo final ficou com 5 variáveis. Os autores se mostraram muito satisfeitos com o modelo proposto, e apontaram em sua conclusão uma precisão de $81,8 \%$ de acerto. A equação de análise discriminante está descrita abaixo (6):

$$
\begin{gathered}
\mathrm{Z}=-0,042+2,909 \mathrm{X}_{1}-0,875 \mathrm{X}_{2}+3,636 \mathrm{X}_{3}+0,172 \mathrm{X}_{4}+0,029 \mathrm{X}_{5}(6) \\
\mathrm{X}_{1}=(\text { ativo circulante }- \text { passivo total) } / \text { ativo total } \\
\mathrm{X}_{2}=(\text { patrimônio líquido }- \text { capital social) } / \text { ativo total } \\
\mathrm{X}_{3}=(\text { lucro operacional }- \text { despesas financeiras }+ \text { receitas financeiras }) / \text { ativo total } \\
\mathrm{X}_{4}=\text { patrimônio líquido } / \text { exigível total } \\
\mathrm{X}_{5}=\text { lucro operacional antes de juros e imposto de renda / despesas financeiras }
\end{gathered}
$$

\subsection{Modelos aplicados em operadoras de saúde: análise integrada}

O trabalho de Barros e Beiruth (2016), base de referência da presente pesquisa, possibilita analisar, de forma comparativa, a conclusão acerca das assertividades dos modelos descritos no item 4, quando estes foram aplicados em todo o grupo de OPS. A seguir, na Tabela o1, é possível analisar o comparativo da performance dos modelos, com base nos dados utilizados pela pesquisa, a época: 
Tabela 1 - Média Dos Anos De 2009, 2010 e 2011 - Resultado.

\begin{tabular}{l|llll}
\hline \multicolumn{1}{c|}{ MODELO } & $\begin{array}{c}\text { INSOLVENTE } \\
\text { CORRETO }\end{array}$ & $\begin{array}{l}\text { SOLVENTE } \\
\text { CORRETO }\end{array}$ & $\begin{array}{c}\text { ERRO } \\
\text { TIPO I }\end{array}$ & $\begin{array}{c}\text { ERRO } \\
\text { TIPO II }\end{array}$ \\
\hline ELIZABETSKY (1976) & $98,90 \%$ & $8,44 \%$ & $\mathbf{1 , 1 0} \%$ & $91,56 \%$ \\
MATIAS (1978) & $75,59 \%$ & $90,64 \%$ & $\mathbf{2 4 , 4 1} \%$ & $9,36 \%$ \\
KANITZ (1978) & $15,01 \%$ & $97,58 \%$ & $84,99 \%$ & $2,42 \%$ \\
ALTMAN ET AL Z1 (1979) & $73,46 \%$ & $56,95 \%$ & $26,54 \%$ & $43,05 \%$ \\
SANVICENTE \& MINARDI & $82,14 \%$ & $28,51 \%$ & $17,86 \%$ & $71,49 \%$ \\
$\begin{array}{l}\text { (1998) } \\
\text { GUIMARÃES \& ALVES (2009) }\end{array}$ & $49,57 \%$ & $23,13 \%$ & $50,43 \%$ & $76,87 \%$ \\
\hline
\end{tabular}

Fonte: Tabela io de (BARROS; BEIRUTH, 2016).

As conclusões daquele estudo foram que, de maneira ordenada decrescente de performance, os melhores modelos foram:

1 - Matias (1978); 2 - Altman; Baidya; Dias (1979); 3 - Sanvicente; Minardi (1998); 4 - Guimarães; Alves (2009); 5 - Kanitz (1978) e 6 - Elizabetsky (1976). Para tanto, utilizou-se como critério de medição de performance os modelos que tiveram maiores percentuais médios nos grupos de Insolvente Correto e Solvente Correto. Como o resultado geral, pode-se inferir que os modelos de Matias (1978) e Altman, Baidya e Dias (1979) foram eficazes na previsão da insolvência das Operadoras de Planos de Saúde no período analisado (BARROS; BEIRUTH, 2016, p. 26).

Vale ressaltar acerca desta conclusão, que era esperado um desempenho melhor do modelo de (GUIMARÃES; ALVES, 2009). Como citado no item 2.2.1, o estudo e modelos foram criados especificamente para as OPS. Foram utilizados dados da mesma fonte, somente com períodos diferentes no estudo de Barros e Beiruth (2016).

\section{Abordagem Metodológica}

A pesquisa se caracteriza como descritiva, com utilização de métodos de análises estatísticas descritivas, aplicados nos resultados de cálculos dos modelos de previsão de insolvência, considerando dados, coletados a partir do sitio da ANS que divulga os dados contábeis de todas as OPS que enviam os dados à agência.

A população correspondeu a todas as Cooperativas OPS que têm os dados divulgados pela ANS no período de 2010 a 2017. Estas quantidades apresentam-se dispostas no Quadro 1 a seguir:

Quadro 1: Quantidade de Cooperativas da Pesquisa por Período.

\begin{tabular}{|c|c|}
\hline Ano & Quantidade Instituições \\
\hline 2010 & 330 \\
\hline 2011 & 326 \\
\hline 2012 & 320 \\
\hline 2013 & 315 \\
\hline 2014 & 308 \\
\hline 2015 & 305 \\
\hline 2016 & 302 \\
\hline & 292 \\
\hline
\end{tabular}

Fonte: Dados Tabulados pelos Autores (2019). 
Após a aplicação dos Modelos a base de dados, foram analisadas suas respectivas performances, observando as seguintes categorias: Acuracidade, Sensibilidade, Especificidade, Média e Área abaixo da Curva de ROC. Ao final, de forma descritiva, apresenta-se, com base na AUC (Área abaixo da Curva ROC), a comparação da performance dos modelos da presente pesquisa, com os resultados apresentados por Barros e Beiruth (2016).

A análise dos dados se deu por meio de softwares conforme os seguintes passos: Download e descompactação dos arquivos de cada Ano do período de 2010 a 2017; Microsoft Power BI para agrupamentos dos arquivos ".csv"; Microsoft Access para tabulação dos dados; Microsoft Excel para cálculos e tabelas; e Software R para cálculos estatísticos.

\section{Apresentação e Análise de Dados}

A presenta seção demonstra os dados, bem como suas respectivas análises, separados nos seguintes tópicos: Análise Descritiva; Aspectos Singulares das Cooperativas OPS; Aplicação dos Modelos de Insolvência; Resultado da Aplicação dos Modelos de Insolvência; e Análise Integrada dos Modelos de Insolvência.

\subsection{Saúde suplementar brasileira em números}

As denominadas Operadoras de Planos de Saúde (OPS), são categorizadas pela Agência Nacional de Saúde (ANS) em "Modalidades", são elas: Autogestão, Cooperativas Médicas, Filantropia, Medicina em Grupo e Seguradoras especializadas em saúde. Tais modalidades, prestam serviços a aproximadamente 47,7 milhões de brasileiros (2016), número que já chegou a 50,4 milhões em 2014.

A Figura o1 a seguir, demonstra a evolução da quantidade de beneficiários desde o ano de 200o. O crescimento acompanhou a evolução da economia brasileira nestes anos demonstrados no gráfico. No ponto de inversão da curva de crescimento, vale ressaltar que a variação do Produto Interno Bruto (PIB) no Brasil, que tinha resultados positivos contínuos nos anos anteriores, foi de 0,50\% em 2014 e negativo nos anos seguintes. Depois de alguns anos de evoluções como 3,97\% em 2011, 1,92\% em 2012 e 3,00\% em 2013, o país teve dois anos seguidos com resultados muito desfavoráveis, os quais foram $-3,77 \%$ em 2015 e $-3,59 \%$ em 2016. Concomitante ao movimento de evolução do PIB, foi possível observar a queda no número de beneficiários de 5,3\% entre os anos de 2014 e 2016, conforme Figura 1 a seguir:

Figura 1: Quantidade de Beneficiários em Panos de Saúde - Milhões.

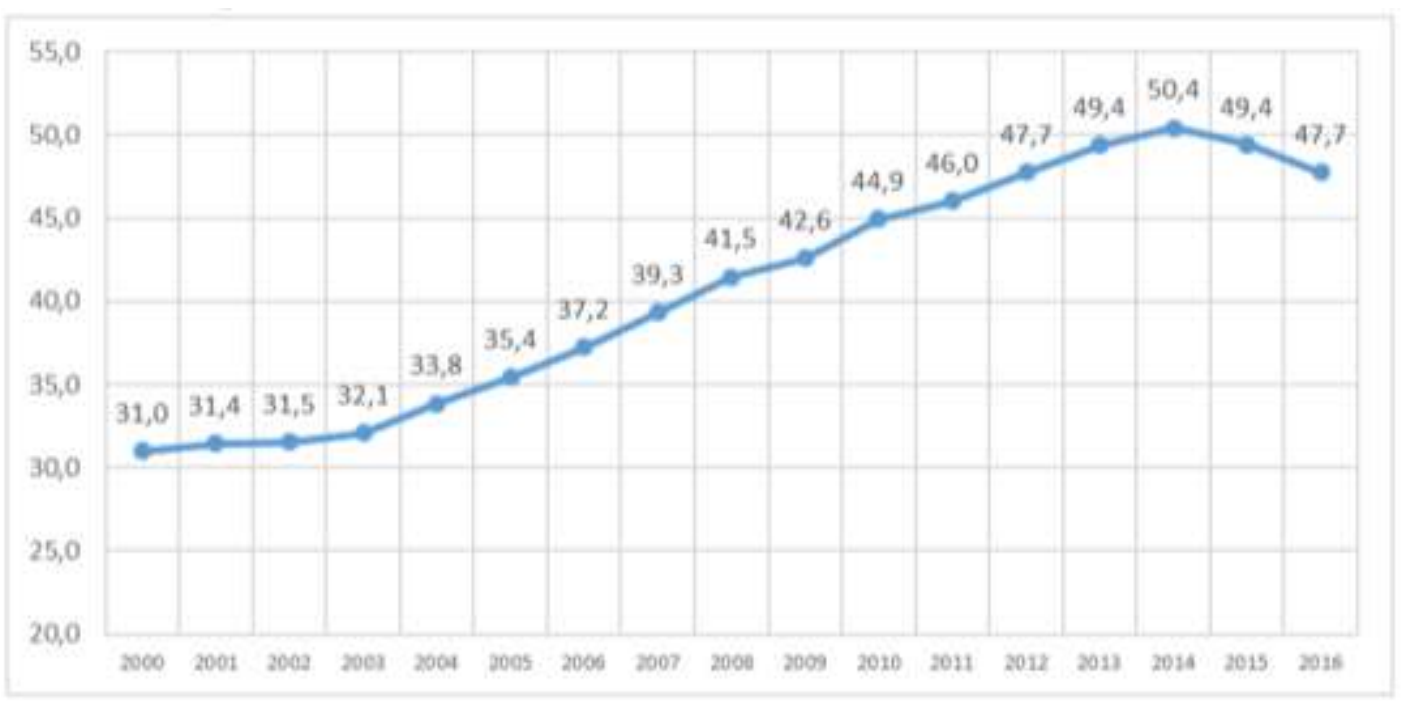

Fonte: Caderno de Informação da Saúde Suplementar (2016). 
Esses beneficiários são atendidos por uma decadente quantidade de OPS ativas, que apresentam queda acentuada desde os anos 2000, gerando maior concentração de instituições no tempo, conforme Figura 2 a seguir:

Figura 2: Quantidade de OPS Ativas.

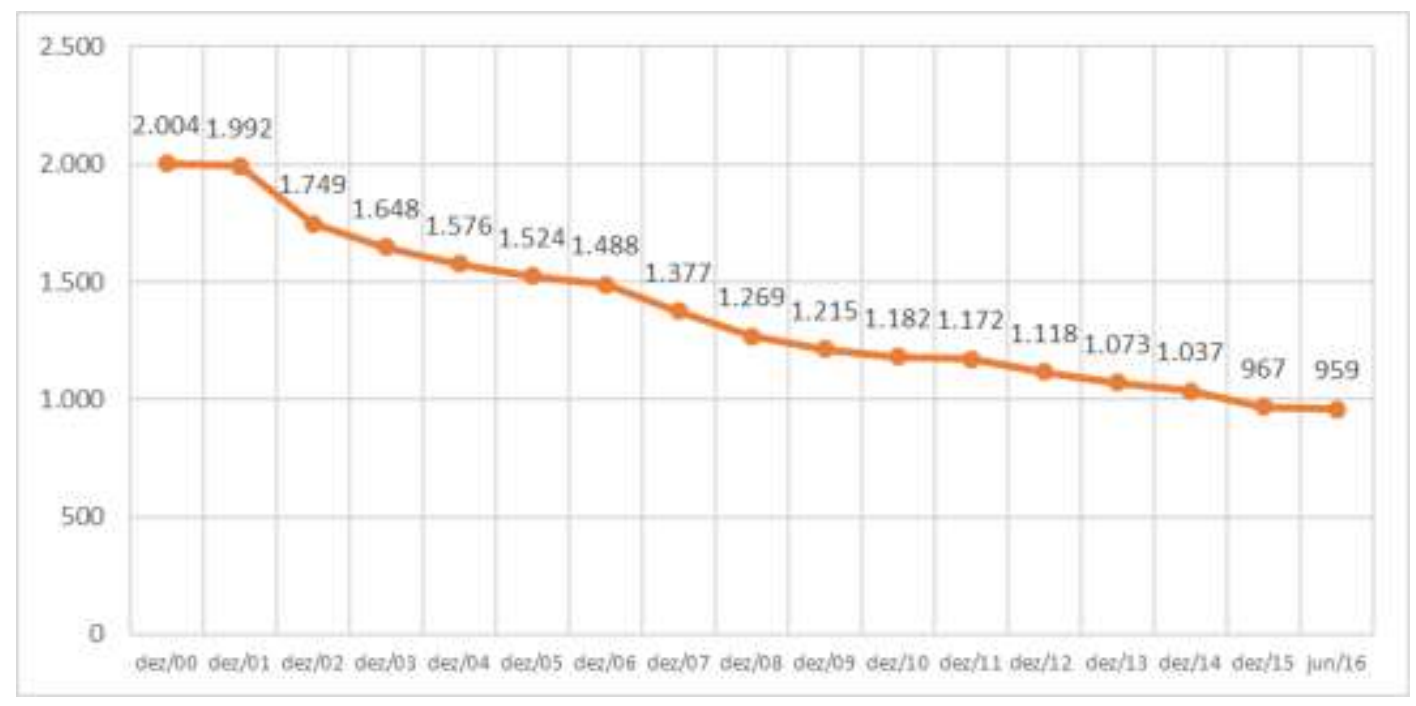

Fontes: SIB/ANS/MS - 06/2016 e CADOP/ANS/MS - 06/2016.

Com relação a quantidade de Beneficiários por Modalidade a Figura 03, a seguir, demonstra que a Modalidade Cooperativas, objeto da presente pesquisa, tem a maior quantidade de beneficiários. Mas ainda se pode observar na mesma figura, que o impacto da redução da quantidade de beneficiários foi mais acentuado nesta modalidade, conforme Figura 3 a seguir:

Figura 3: Quantidade de Beneficiários Por Modalidade de OPS - Milhões.

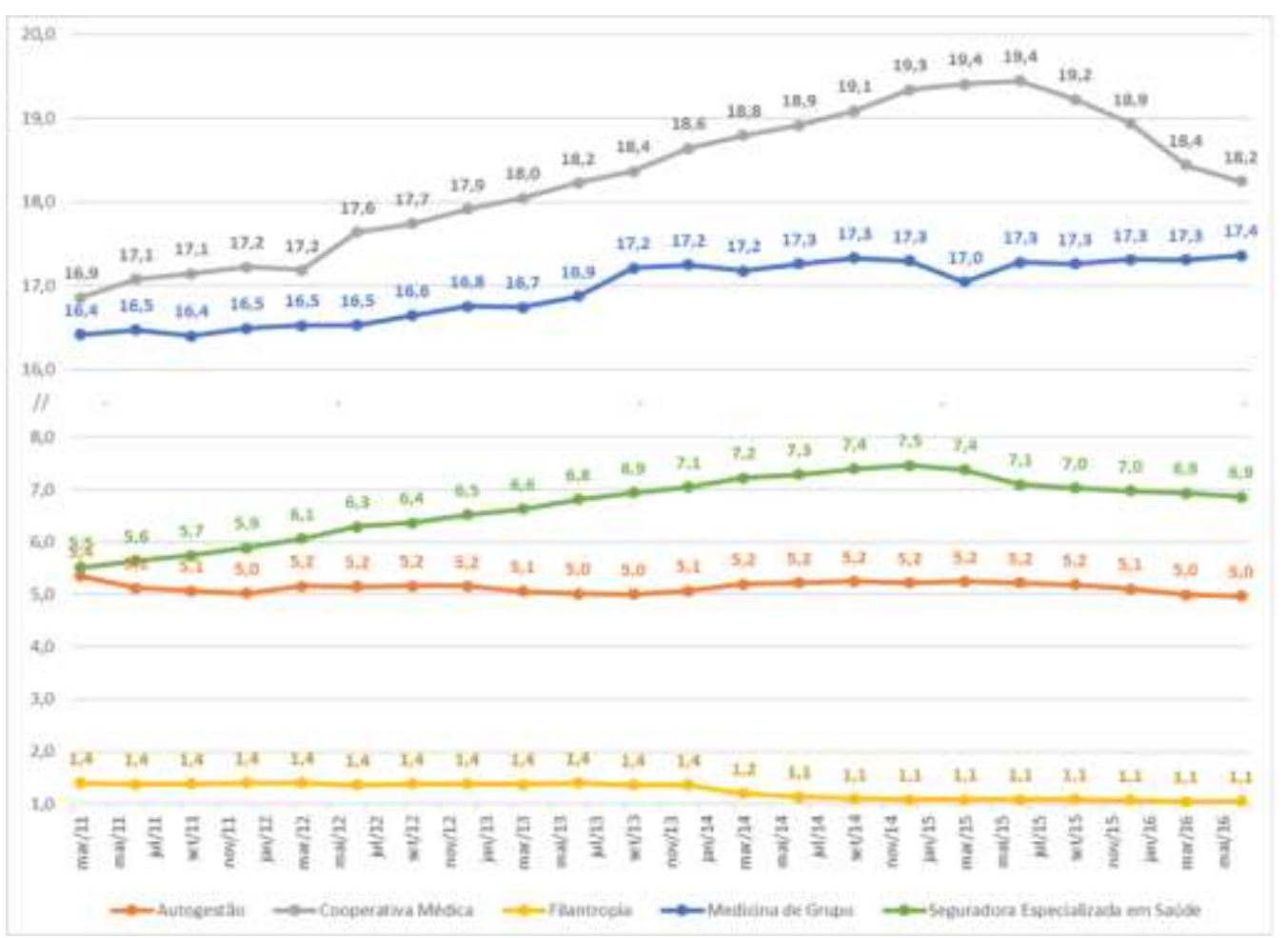

Fonte: SIB/ANS/MS - 06/2016 e CADOP/ANS/MS - 06/2016. 
O total de OPS ativas passou de 2.004 entidades no ano de 2010 para 959 em junho de 2016. Ainda no relatório de OPS canceladas no período (sem considerar as inclusões), as Medicinas de Grupo foram as mais afetadas com 947 cancelamentos, seguidas pelas Auto-Gestão com 369 e as Cooperativas com 89 cancelamentos em 16 anos.

A Lei 9656/98 define as OPS como empresas que exercem as atividades de administração, comercialização ou disponibilização dos planos de saúde. Elas têm a finalidade de garantir a assistência médica, hospitalar e odontológica a seus contratantes, sem limite financeiro para estas garantias.

Neste sentido foram criadas algumas medidas de controle e de proteção ao usuário, como o Plano de Contas Padrão que objetivou a uniformização da Contabilidade, facilitando o controle econômico financeiro; e o Sistema de Garantias e Provisões Técnicas, que garantiu provisões financeiras suplementares para que as OPS tivessem como cumprir seus compromissos quando em dificuldades (ARAÚJO, 2004).

A ANS em sua RN no 209 (BRASIL, 2009) dispõem sobre as Reservas Técnicas necessárias para composição de "Margem de Solvência". Dentre as questões colocadas pela agência, existe a proposição de até o ano de 2022, as OPS tenham em seu Patrimônio Líquido um valor maior que 1/3 da soma dos últimos 36 meses de Custo Assistencial. Em outras palavras, o Patrimônio Líquido deve ser maior do que o dispêndio médio anual que uma OPS teve nos últimos 3 anos, com custo de tratamento e assistência aos seus beneficiários.

Atualmente, o mercado de OPS no Brasil registrou ao final do ano de $2016 \mathrm{R} \$ 116$ bilhões em Ativos Contábeis, como observado na Figura o4, este valor é quase o dobro do valor ao final do ano de 2010, conforme Figura 4 a seguir:

Figura 4: Evolução dos Ativos Totais das OPS - Bilhões de Reais.

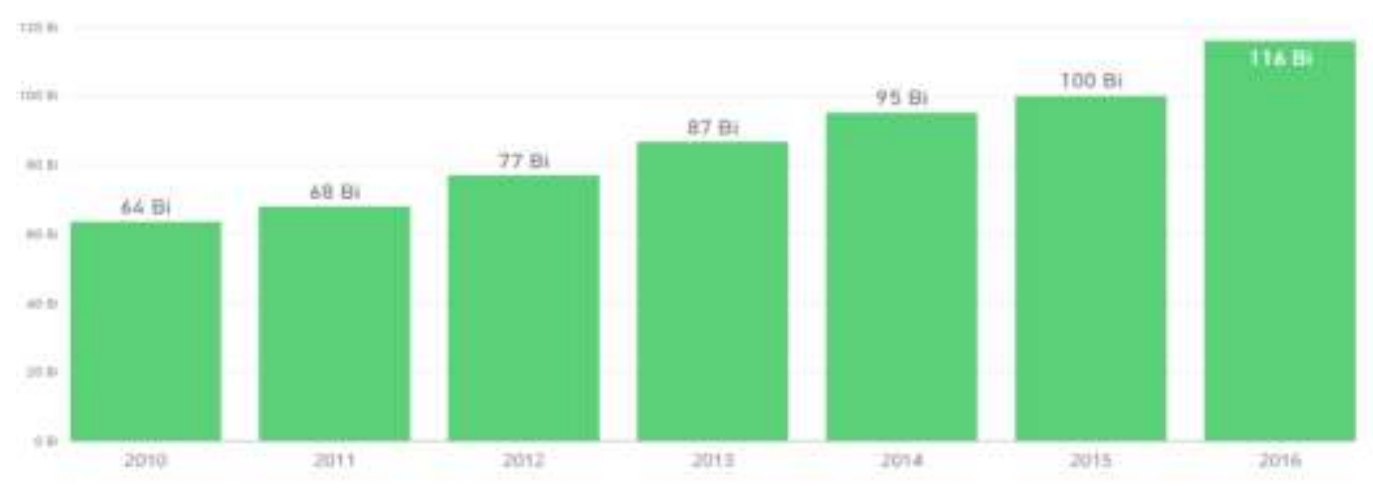

Fonte: Dados Tabulados pelos Autores (2019).

Embora os ativos totais das OPS mostrem-se crescentes, sua estrutura econômica operacional é marginal, auferindo números igualmente impressionantes de receitas e despesas, cujas evoluções percentuais, apresentam-se discretamente deslocadas, pois, as Receitas apresentam aumento de $104,3 \%$ no período de 2010 a 2016 , enquanto as despesas cresceram 105,6\% no mesmo período, conforme Figura 5 a seguir: 
Figura 5: Evolução das Despesas e Receitas das OPS - Bilhões de Reais.

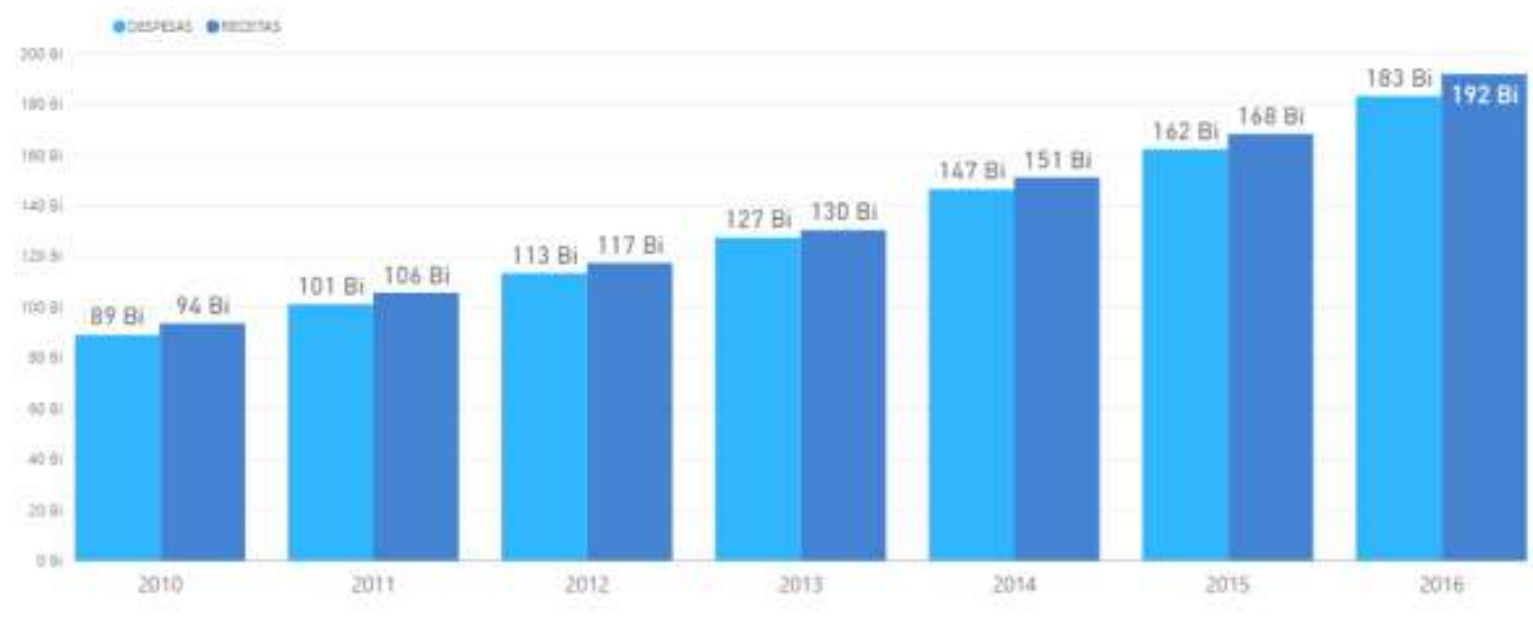

Fonte: SIB/ANS/MS - 06/2016 e CADOP/ANS/MS - 06/2016.

De forma ainda inicial, já é possível perceber que, embora a ANS em sua RN no 209 (BRASIL, 2009) procure promover maior estabilidade a esse mercado, por meio de Reservas Técnicas para composição de "Margem de Solvência", em geral, os Patrimônios Líquidos atuais, apresentam-se diante de um intrigante desafio para os próximos anos, pois seus valores estão longe de corresponder às exigências da norma, o que deve, provocar importantes ações em busca da diminuição do custo de sinistralidade de seus usuários.

Mais especificamente, em se tratando de Organizações Cooperativas na Área de Saúde, existe um notório decrescimento quantitativo, conforme demonstrado na Tabela 03, no período de 2010 a 2017, ocorreu uma queda de $28,9 \%$ no número de operadoras, sendo estas divididas em dois grupos: Cooperativas Odontológicas; e Cooperativas Médicas.

Quando observado o grupo de OPS Médicas, é possível ver a evolução das Cooperativas Médicas assumindo o posto de maior modalidade em quantidade de empresas. Enquanto as empresas de Medicina de Grupo tiverem uma queda no número de operadoras de 30,4\%, as Cooperativas tiveram uma redução de $11,5 \%$.

A Tabela 2, a seguir, demonstra a quantidade de OPS por grupos e modalidades. Vale ressaltar ainda, que, somente as Cooperativas Médicas, figuram com objeto da presente pesquisa, sendo utilizado como Base de Dados, a totalidade das informações das instituições dessa modalidade.

Tabela 2 - Quantidade de OPS por Grupo, Modalidade e Ano.

\begin{tabular}{|c|c|c|c|c|c|c|c|c|}
\hline GRUPO E MODALIDADE & 2010 & 2011 & 2012 & 2013 & 2014 & 2015 & 2016 & 2017 \\
\hline ODONTOLÓGICAS & 367 & 355 & 342 & 331 & 330 & 320 & 301 & $\mathbf{2 8 8}$ \\
\hline COOPERATIVA ODONTOLÓGICA & 118 & 117 & 116 & 112 & 111 & 109 & 107 & 104 \\
\hline ODONTOLOGIA DE GRUPO & 249 & 238 & 226 & 219 & 219 & 211 & 194 & 184 \\
\hline MÉDICAS & 922 & 895 & 856 & 838 & 803 & $77^{2}$ & 752 & 719 \\
\hline AUTOGESTÃO & 133 & 130 & 126 & 125 & 128 & 128 & 126 & 122 \\
\hline COOPERATIVA MÉDICA* & 330 & 326 & 320 & 315 & 308 & 305 & 302 & 292 \\
\hline
\end{tabular}


FILANTROPIA

MEDICINA DE GRUPO

SEGURADORA ESPEC. EM SAÚDE

TOTAL GERAL

\begin{tabular}{cccccccc}
88 & 82 & 77 & 72 & 62 & 57 & 52 & 46 \\
359 & 344 & 320 & 314 & 294 & 272 & 262 & 250 \\
12 & 13 & 13 & 12 & 11 & 10 & 10 & 9 \\
1289 & 1250 & 1198 & 1169 & 1133 & 1092 & 1053 & 1007 \\
\hline
\end{tabular}

Fonte: Dados Tabulados pelos Autores (2019).

Ao observarmos a totalidade de Receitas que envolvem essas entidades, pode-se perceber, na Figura 6, a seguir, a evolução histórica, segregados por modalidades, destas, a modalidade com maior faturamento, corresponde as Cooperativas Médicas, seguida da Medicina de Grupo, conforme apresentado a seguir:

Figura o6 - Evolução das Receitas das OPS por Modalidade - Bilhões de Reais.

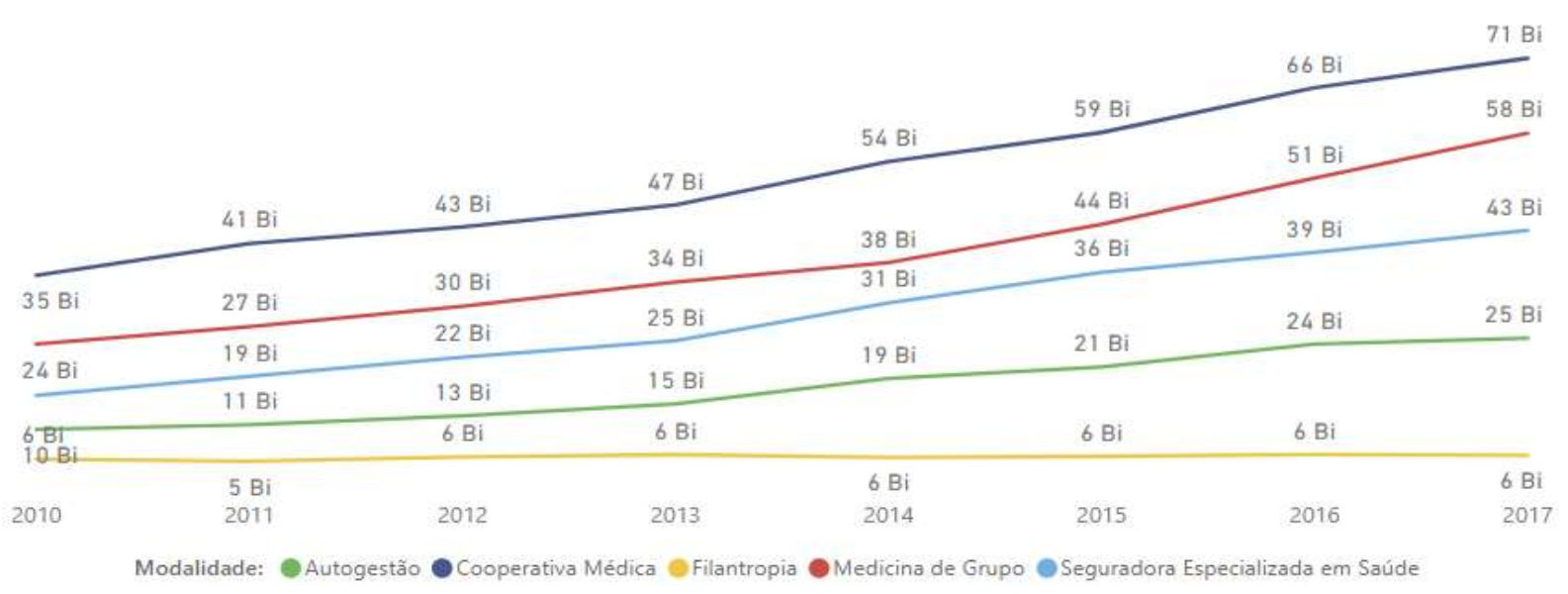

Fonte: Dados Tabulados pelos Autores (2019).

\subsection{Aplicação dos modelos de previsão de insolvência}

As aplicações dos modelos de previsão de insolvência, para fins de método, ocorreram com dados do ano $x$ para prever a Insolvência do ano $x+1$. Por exemplo, o modelo utilizou os dados do ano de 2010 para prever a Insolvência no ano de 2011 e assim sucessivamente.

Para medir a eficácia de cada modelo foram cridas as matrizes de confusão, onde são cruzados os dados de forma que seja verificada a quantidade de observações que eram efetivamente positivas e o modelo classificou como positivas, assim como as originalmente negativas e sua respectiva classificação pelo modelo. Desta forma são quatro as resultantes desta classificação: Positivo-Positivo, Falso-Falso, Positivo-Falso e Falso-Positivo. Com base nesta matriz foi possível calcular os seguintes indicadores analisados anualmente:

a. Índice de Sensibilidade (Insolvente Correto) - Percentual de OPS classificadas como Insolvente Corretamente pelo modelo sobre o total de OPS Insolventes;

b. Índice de Especificidade (Solvente Correto) - Percentual de OPS classificadas como Solvente corretamente pelo modelo sobre o total de OPS Solventes;

c. Índice de Acuracidade (Insolvente Correto + Solvente Correto) - Percentual de Insolventes Corretos e Solventes Corretos sobre o total da Amostra. 
A seguir, na Tabela 3, é possível comparar os resultados de todos os modelos aplicados, observando sua Acuracidade, Sensibilidade, Especificidade, Média e Área abaixo da Curva de ROC.

Tabela 3 - Resultado de Previsão por Modelo - Comparação Geral.

\begin{tabular}{l|c|c|c|c|c}
\hline Modelo & Acuracidade & $\begin{array}{c}\text { Sensibilidade } \\
\text { Insolvente Correto }\end{array}$ & $\begin{array}{c}\text { Especificidade } \\
\text { Solvente Correto }\end{array}$ & $\begin{array}{c}\text { Média (Sensib. e } \\
\text { Especif.) }\end{array}$ & $\begin{array}{c}\text { AUC (Área abaixo } \\
\text { da Curva ROC) }\end{array}$ \\
\hline Guimarães e Alves & $95,6 \%$ & $65,7 \%$ & $96,0 \%$ & $80,9 \%$ & $92,0 \%$ \\
Elizabetsky & $4,0 \%$ & $100,0 \%$ & $0,0 \%$ & $50,0 \%$ & $87,2 \%$ \\
Matias & $88,0 \%$ & $85,6 \%$ & $88,2 \%$ & $86,9 \%$ & $92,9 \%$ \\
Kanitz & $93,8 \%$ & $17,9 \%$ & $97,0 \%$ & $57,4 \%$ & $70,5 \%$ \\
Altman, Baidya e & $68,6 \%$ & $93,1 \%$ & $67,6 \%$ & $80,4 \%$ & $92,8 \%$ \\
Dias & & & & & $74 \%$ \\
Sanvicente e & $14,3 \%$ & $93,2 \%$ & $11,0 \%$ & $52,1 \%$ & $74,4 \%$ \\
Minardi & & &
\end{tabular}

Fonte: Dados Tabulados pelos Autores (2019).

Em complemento, na Figura 7, a seguir, é possível observar a distribuição dos valores entre os resultados da equação, com um histograma parcial.

Figura 7 - Curva ROC e AUC - Todos os Modelos.

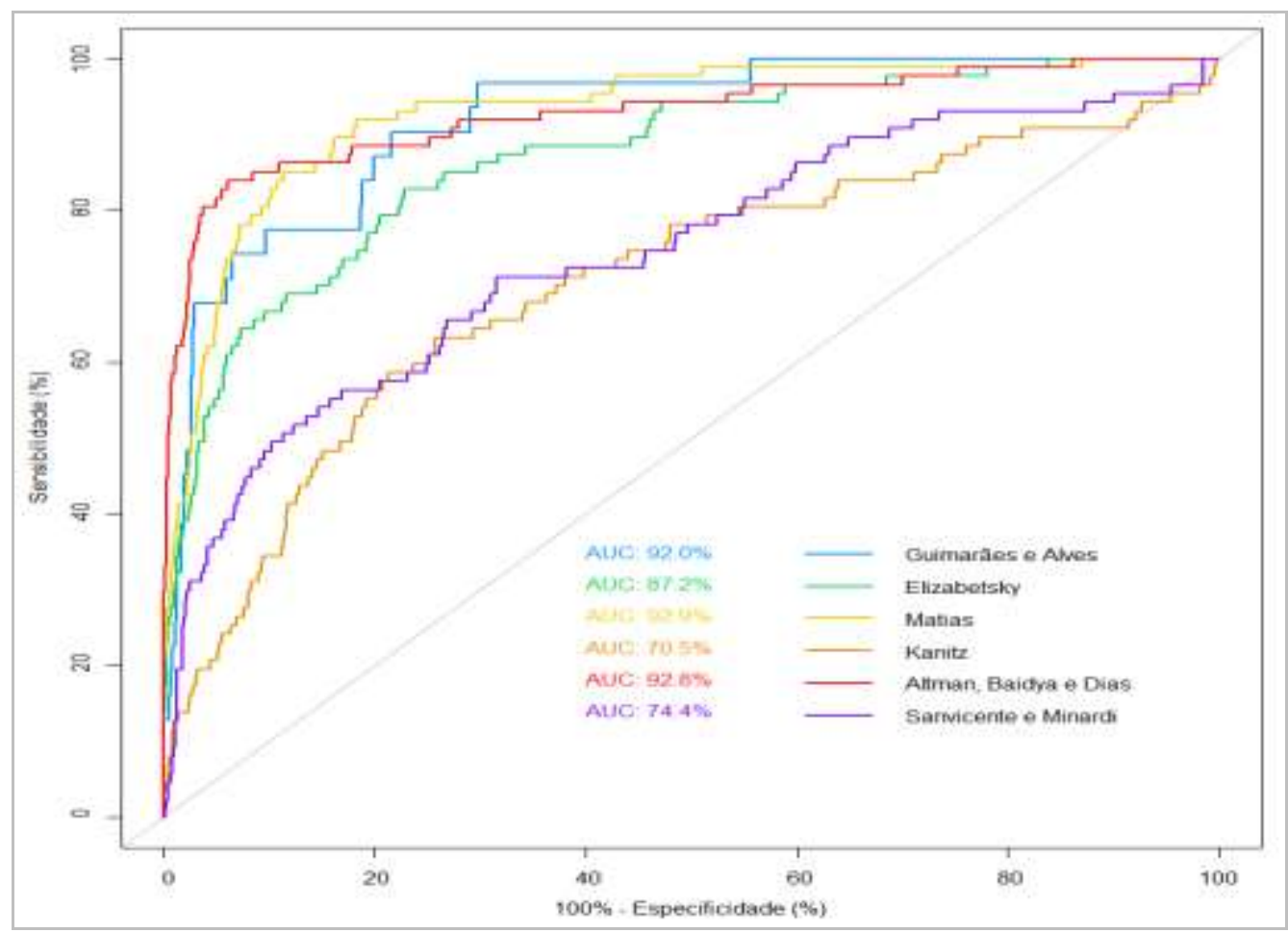

Fonte: Dados Tabulados pelos Autores (2019).

Ao comparar todas as Curvas ROC dos modelos, é possível observar o desempenho das equações com diferentes pontos de corte, sempre cruzando a Sensibilidade com a Especificidade (100\% - Especificidade nestes gráficos).

Os modelos de Kanitz, Sanvicente e Minardi, e Elizabetsky tiverem desempenho baixo, repetindo os resultados alcançados por (BARROS; BEIRUTH, 2016) com exceção ao modelo de Sanvicente e Minardi.

Mais especificamente, na análise do modelo de Elizabetsky, um elemento vale ser ressaltado: A variável $\mathrm{X}_{4}$ do modelo (Estoque/Ativo Total) apresenta sinal positivo na equação. Por característica de OPS, não faria sentido ter um elevado valor em estoque, pois em sua maioria a rede 
de atendimento é credenciada e a OPS teria somente um estoque de estrutura administrativa. Este ponto e a linha de corte do modelo $(0,5)$ podem ser os motivos do resultado da equação de Elizabetsky ter classificado como "Insolvente" a grande maioria das OPS.

O modelo de Guimarães e Alves (2009), desenvolvido especificamente para aplicação em operadoras de planos de saúde, demonstra resultante de $96 \%$ de capacidade de classificar as OPS Solventes. No entanto, ao classificar as OPS Insolventes, conseguiu um índice de apenas $65,7 \%$. Vale ressaltar que este é o único modelo a usar Regressão Logística como técnica estatística, enquanto os demais utilizaram Análise Discriminante.

Nesse contexto, baseado no indicador de AUC, os modelos, cujas resultantes, apresentam-se melhor adequadas as instituições foco da pesquisa, em ordem de performance, foram: Matias; Altman, Baidya e Dias; e Guimarães e Alves.

Em comparação com o estudo de Barros e Beiruth (2016), pode-se perceber uma sutil diferença de performance entre os modelos, conforme Quadro 2, a seguir:

Quadro 2 - Comparação de resultantes de Aplicação dos Modelos - Por Ordem de Performance.

\begin{tabular}{|l|l|}
\hline \multicolumn{1}{|c|}{ Pesquisa Barros \& Beiruth (2016) } & \multicolumn{1}{c|}{ Pesquisa Atual } \\
\hline Matias & Matias \\
\hline Altman, Baidya \& Dias & Altman, Baidya \& Dias \\
\hline Sanvicente e Minardi & Guimarães \& Alves \\
\hline Guimarães \& Alves & Elizabetsky \\
\hline Kanitz & Sanvicente e Minardi \\
\hline Elizabetsky & Kanitz \\
\hline
\end{tabular}

Fonte: Dados Tabulados pelos Autores (2019).

Dentre as diferenças de resultado entre as pesquisa, o modelo de Guimarães e Alves, apresenta-se entre os três melhores modelos da presente pesquisa, figurando anteriormente na posição de número quatro. Já o modelo de Sanvicente e Minardi, que apareceu entre os três melhores no estudo citado, teve um rigor muito alto ao classificar excessivamente as OPS como Insolventes no estudo atual.

Apesar do índice de acuracidade do modelo de Matias ser o terceiro melhor escore de $88 \%$, considerando a capacidade de classificar corretamente tanto as cooperativas Insolventes $(85,6 \%)$ quanto as Solventes $(88,2 \%)$, pode se considerar que o modelo de Matias, apresenta-se como a melhor opção de aplicação para análise de previsão de Insolvência, em instituições assemelhadas as da presente pesquisa, pois obteve o melhor desempenho na classificação.

Tal performance, em parte, se deve, a variável X1 da equação: “23,792 Xı”, onde X1 = PL / AT, ou seja, o modelo de Matias considera com grande peso (23,792) a razão do Patrimônio Líquido sobre o Ativo Total. Sendo o Patrimônio Líquido o indicador de Solvência, a própria estrutura da equação já o utiliza de forma a indicar a Insolvência do ano seguinte.

\section{Considerações finais}

A relevância do uso de um modelo de Insolvência adequado a instituições cooperativas da área de saúde, apresenta-se diretamente relacionada a importância dessas instituições perante a sociedade. Tal relevância se agrava, no contexto brasileiro, que provoca a necessidade da qualificação assistencial, jurídica e econômica dessas instituições.

Nesse contexto, pautado no propósito de qualificar a servidão das finanças junto a esse mercado em específico, a presente pesquisa, apresentou um diagnóstico qualificado acerca da representatividade econômica, social e estrutural das cooperativas médicas operadoras de Planos de Saúde, servindo-se da base de dados da ANS, nos períodos de 2010 a 2017, afim de propor o uso de 
modelagem específica de análise de Insolvência, que melhor se adeque a realidade desse mercado no contexto brasileiro.

A proposição de modelo, perpassou pela análise e aplicação de seis modelos específicos, a exemplo da pesquisa de referência (BARROS; BEIRUTTI, 2016). No entanto, embora haja alguma semelhança no propósito da presente pesquisa e da pesquisa de referência, suas conclusões apresentam-se sutilmente distintas, pois as performances dos modelos, pautados no AUC, mostraram-se diferentes.

Diferente da pesquisa de referência de Barros e Beirutti (2016), na presente pesquisa, após aplicação e análise de seis modelos clássicos de previsão de Insolvência, se obteve como resultado, a seguinte escala de performance: (1) Matias; (2) Altman, Baidya e Dias; e (3) Guimarães e Alves. Os modelos apresentaram forte equiparação de análises focados no trabalho com destaque para o modelo que tinha tecnicamente regressão logística direcionada a análise de Operadoras de Planos de Saúde OPS. Porém apresentando baixa sensibilidade em classificação de insolventes, necessitando analisar este outro ponto com outro modelo mais aderente ao processo.

Diante do exposto, embora tal proposição apresente-se consistente e contributiva em sua base de dados, período de análise e de modelos analisados, deve-se ressaltar que com a evolução tecnológica e a maior capacidade de processamento de informações, surgiram modelos estatísticos mais complexos e dedicados a classificação de categorias em bases de dados. Dentre estes modelos é possível citar: Regressão Logística, Árvores de Decisão, SMV - Support Vector Machine (Máquinas de Suporte Vetorial), RNA - Redes Neurais Artificiais, Naive Bayes, Random Forest, entre outros (ACADEMY, 2019). Com esta capacidade de tratamento de dados, seria possível adicionar e testar mais variáveis a esse mercado em específico, como por exemplo dados da abrangência da OPS (municipal, regional, Nacional), o porte da OPS (pequeno, médio ou grande porte), a quantidade e a evolução da quantidade de beneficiários, a estrutura da rede de prestadores (credenciada, própria, mista), a quantidade de Médicos Cooperados, entre outros.

Tais testes podem levar a derivação de uma nova modelagem de previsão de insolvência, a partir das variáveis e realidades já compreendidas, elevando a qualificação e acurácia de mitigação de riscos, a essa importante, relevante e intrigante área de atuação, gerando uma resposta efetiva a constituição de uma margem de Solvência, conforme citado na RN no 209 (BRASIL, 2009) e reforçado pela RN no 443 (BRASIL, 2019).

\section{Referências}

ACADEMY, D. S. DataScience Academy. DataScience Academy - Deep Learning Book, 2019. Disponivel em: www.deeplearningbook.com.br. Acesso em: 15 mar.2019.

AHERN, M. The evolution and impact of state HMO regulation: a case of study. Journal of Insurance Regulation, Florida, v. 10, n. 1, p. 110-127, 1991.

ALTMAN, E. I. Financial Ratios, Discriminant Analysis And The Prediction Of Corporate Bankruptcy. The Journal of Finance, v. 23, n. 4, p. 589-609, September 1968.

ALTMAN, E. I.; BAIDYA, T. K. N.; DIAS, L. M. R. Previsão de problemas financeiros em empresas. Revista de Administração de Empresas, v.19, 1979. 17-28.

ANDRICH, E. G.; CRUZ, J. A. W. Gestão Financeira Moderna: uma abordagem prática. Editora Intersaberes, 2013. 
ANDRICH, E. G.; CRUZ, J. A. W.; ANDRICH, R. G.; GUINDANI, R. A. Finanças Corporativas: Análise de Demonstrações Financeiras e de Investimentos. Editora Intersaberes, 2014.

ANS. Resolução de Diretoria Colegiada no 39, de 28 de janeiro de 200o. Definição, a segmentação e a classificação das Operadoras de Planos de Assistência à Saúde, Brasília - DF, 28 jan 2000.

ANS. Sala de Situação. Sala de Situação - Dados e Indicadores do Setor, 2017. Disponivel em: www.ans.gov.br/perfil-do-setor/dados-e-indicadores-do-setor/sala-de-situacao. Acesso em: out. 2017.

ARAÚJO, C. M. Estudo para elaboração do manual de procedimentos do diretor fiscal de operadoras de plano de saúde para regimes especiais. Dissertação (Mestrado em Regulação em Saúde Complementar) - Escola Nacional de Saúde Pública, Rio de Janeiro, p. 143, 2004.

BARROS, J.; BEIRUTH, A. X. Aplicação de Modelos de Previsão de Insolvência nas Operadoras de Planos de Saúde do Brasil. Revista de Auditoria Governança e Contabilidade, 4(15), p. 15-28, 2016.

BEAVER, W. H. Financial ratios as predictors of failure. Journal of Accounting Research, Chicago, v. 4, p. 71-11, 1966.

BIALOSKORSKI NETO, S. Aspectos Econômicos das Cooperativas. São Paulo: Mandamentos, v. 7, 2006.

BIALOSKORSKI NETO, S. Economia e Gestão de Organizações Cooperativas. 2a. ed. São Paulo: Atlas, 2012.

BRASIL. Lei n. 10.185, de 14 de fev. de 2001. Dispõe Sobre A Especialização Das Sociedades Seguradoras Em Planos Privados De Assistência A Saúde, Brasília, DF, 14 fev 2001.

BRASIL. Resolução Normativa no 209, 22 de dezembro de 2009. Recursos Próprios Mínimos e constituição de Provisões Técnicas, Brasília, DF, 22 dez 2009.

BRASIL. Resolução Normativa no 443, 25 de janeiro de 2019. Adoção de Práticas Mínimas de Governança, Controles internos e Gestão de riscos, para fins de solvência das operadoras de plano de assistência à saúde, Brasília, DF, 22 Jan 2019.

BRASIL, G. D. Demonstrações Contábeis ANS. Portal Brasileiro de Dados Abertos, 2018. Disponivel em: dados.gov.br/dataset/http-www-ans-gov-br-perfil-do-setor-dados-abertos-dados-abertosdisponiveis-n3. Acesso em: 05. de.dez.2018.

CHAVES, V. M.; ZDZIARSKI, A. D.; CRUZ, J. A. W.; DA SILVA, W. V.; DA SILVA, C. L. Análise da eficiência do atendimento do sistema único de saúde nos municípios paranaenses. Journal of Globalization, Competitiveness \& Governability, v. 11, n. 2, 2017.

CRUZ, J. A. W.; ANDRICH, E. G.; SCHIER, C. U. C. Contabilidade Introdutória Descomplicada, Editora Juruá, 6 Edição, 2019.

CRUZ, J. A. W.; ANDRICH, E. G.; MUGNAINI, A. Análise de Demonstrações Financeiras: Teoria e Prática, Editora Juruá, 4 Edição, 2019.

ELIZABETSKY, R. Um modelo matemático para decisão de crédito no banco comercial. Escola Politécnica da Universidade de São Paulo, São Paulo, 1976. 19op.

FAMÁ, R.; GRAVA, J. W. Liquidez e a Teoria dos Elementos Causadores. FEA-USP Caderno de Pesquisas em Administração, São Paulo, v. o1, n. 12, 2000. 
FENASAÚDE. CNSEG - O que é Saúde Suplementar. Estrutura do Mercado de Saúde Suplementar, 2019. Disponivel em: cnseg.org.br/fenasaude/sobre-o-setor/. Acesso em: 10.de.mar.2019.

GUIMARÃES, A. L. S.; ALVES, W. O. Prevendo a Insolvência de Operadoras de Planos de Saúde. Revista de Administração de Empresas, n. 4, v. 49, p. 459-471, 2009.

KANITZ, S. C. Como prever falências. São Paulo: McGraw do Brasil, 1978.

LEAL, R. M.; MATOS, J. B. B. D. Planos de saúde: uma análise dos custos assistenciais e seus componentes. Revista de Administração de Empresas v. 49, n. 4, São Paulo, p. 447-458, dez 2009.

LEV, B. The aggregation problem in financial statements: An informational approach. Journal of Accounting Research, Chicago, v. 6, n. 2, p. 247-261, Autumn 1968.

MATIAS, A. B. Indicadores contábeis e financeiros de previsão de insolvência: a experiência da pequena e média empresa. Faculdade de Economia e Administração de São Paulo, São Paulo, 1976.

MOREIRA, R. Conhecendo a Unimed. 2. ed. Curitiba: Kairos, 2012.

PINHEIRO, L. E. T. et al. Validação de Modelos Brasileiros de Previsão de Insolvência. Contabilidade Vista \& Revista, Belo Horizonte, v. 18, n. 4, p. p.83-p.103, out./dez. 2007.

SALLES DIAS FILHO, P. P. Encarando um mundo instável e incerto: experiências regulatórias face aos riscos relativos aos seguros-saúde. Dissertação de Mestrado em Saúde Coletiva - UERJ, Rio de Janeiro, 2010.

SANVICENTE, A. Z.; MINARDI, A. M. A. F. Identificação de indicadores contábeis significativos para previsão de falência de empresas. Finance LabWorking Papers, Ibmec, São Paulo, 1998.

SCALZER, R. S.; RODRIGUES, A.; DA SILVA MACEDO, M. Á. Insolvência empresarial: um estudo sobre as distribuidoras de energia elétrica brasileiras. Revista Contemporânea de Contabilidade, Florianópolis, v. 12, n. 27, p. 27-6o, set./dez. 2015. ISSN 2175-8069.

UNIMED. Unimed do Brasil - Institucional. Unimed do Brasil, 2017. Disponivel em: www.unimed.coop.br/home/sistema-unimed/a-unimed/unimed-do-brasil. Acesso em: dez. 2017.

VIANA, A. D. F. et al. Um estudo sobre a Insolvência das Operadoras de Planos de Saúde. EnANPAD, Rio de Janeiro, p. 14, set. 2012. 